\title{
PURIFICAÇÃO DE NÍQUEL VIA EXTRAÇÃO POR SOLVENTES COM CYANEX 272 E ÁCIDO NAFTÊNICO
}

\author{
A.S. GUIMARÃES ${ }^{1}$, P.S. da SILVA ${ }^{1}$ e M.B. MANSUR ${ }^{1}$ \\ ${ }^{1}$ Universidade Federal de Minas Gerais, Departamento de Engenharia Metalúrgica e de Materiais \\ E-mail para contato: alexandre.guimaraes6@gmail.com; marcelo.mansur@demet.ufmg.br
}

\section{RESUMO}

A técnica de extração por solventes foi avaliada na purificação de níquel, contido em soluções aquosas sintéticas sulfúricas, diante das impurezas cálcio, cobalto, cobre, magnésio, manganês e zinco, em níveis de concentração semelhantes aos licores industriais obtidos pelo processo de lixiviação sob pressão de minérios lateríticos. A solução pode ser pré-purificada em relação aos metais $\mathrm{Co}, \mathrm{Cu}, \mathrm{Mn}$ e $\mathrm{Zn}$, em pH = 3,9 e $50^{\circ} \mathrm{C}$, utilizando-se $20 \%$ v/v de Cyanex 272 , em estágios, com perda de níquel de apenas $0,5 \%$. Os metais alcalinos terrosos cálcio e magnésio, ao contrário dos demais, não são extraídos seletivamente com Cyanex 272 (20\% v/v) em relação ao níquel. Nesse sentido, misturas contendo Cyanex 272 e ácido naftênico foram avaliadas no intuito de purificar o licor contendo $\mathrm{Ca}, \mathrm{Mg}$ e $\mathrm{Ni}$. Observou-se que a mistura de $20 \%$ v/v de Cyanex 272 e $10 \%$ v/v de ácido naftênico é seletiva, em $\mathrm{pH}=5,0$ e $50^{\circ} \mathrm{C}$, por promover a extração de cerca de $20 \%$ de cálcio, $60 \%$ de magnésio, conjuntamente com baixas remoções de níquel, cerca de $3 \%$. Tal condição possibilita a purificação da solução em relação ao níquel, na presença dos contaminantes cálcio e magnésio, podendo-se utilizar em torno de 3-4 estágios de contactação para se obter um refinado com cerca de $90 \%$ de níquel purificado. 


\section{9 a 22 de outubro de 2014 \\ Florianópolis/SC}

\section{INTRODUÇÃO}

O níquel possui elevada relevância comercial nas commodities minerais brasileiras. O país detém a terceira maior reserva mineral de níquel conhecida no mundo, estimada em 8,4 milhões de toneladas (U.S. Geological Survey, 2014). Segundo Moskalyk e Alfantazi (2002), níquel é encontrado em depósitos de minérios sulfetados e lateríticos. Industrialmente, a lixiviação de minérios lateríticos pode ser realizada com ácido sulfúrico sob condições de elevadas temperaturas (entre 250 e $270^{\circ} \mathrm{C}$ ) e pressões (entre 1 e 2 atm), processo denominado de $\mathrm{High}$ Pressure Acid Leaching (HPAL). O licor obtido nessa etapa, após a precipitação de ferro (Rydberg et al., 2004), possui cálcio, cobalto, cobre, magnésio, manganês, níquel e zinco. A separação dessas espécies metálicas em relação ao níquel pode ser realizada por via hidrometalúrgica utilizando-se a técnica de extração por solventes (Sun, 2010), que permite a obtenção de metais com elevado teor de pureza (Lo et al., 1993). O processo industrial de extração por solventes que promove a separação cobalto/níquel é amplamente utilizado com o extratante Cyanex 272 (ácido 2,4,4-trimetil-pentil fosfínico), por apresentar elevada seletividade pelo cobalto em relação ao níquel (Devi et al., 1998; Nayl, 2010). No entanto, conforme observado por Flett (2005), o Cyanex 272 apresenta baixa seletividade na separação do níquel diante de metais alcalinos terrosos. Com isso, a purificação de níquel em relação aos contaminantes cálcio e magnésio pode ser melhorada utilizando-se sistemas extrativos sinérgicos, que são obtidos misturando-se dois ou mais extratantes comercialmente disponíveis. Atualmente, os sistemas extratores sinérgicos têm sido alvo de estudos para a purificação de níquel visto tratar-se de uma alternativa econômica e que pode ser implementada industrialmente sem grandes transtornos (Cheng et al., 2006; Ndlovu e Mahlangu, 2008). Diante do exposto, este trabalho propõe avaliar o uso de Cyanex 272, ácido naftênico e misturas entre Cyanex 272 e ácido naftênico almejando-se promover a purificação de níquel contido em licores sintéticos sulfúricos em relação às impurezas cálcio, cobalto, cobre, manganês, magnésio e zinco.

\section{PROCEDIMENTO EXPERIMENTAL}

\subsection{Licor sintético sulfúrico}

A fase aquosa foi preparada com os metais de interesse $(\mathrm{em} \mathrm{mol} / \mathrm{L})$ : $[\mathrm{Ca}]=0,013 ;[\mathrm{Co}]=$ 0,$034 ;[\mathrm{Cu}]=0,004 ;[\mathrm{Mn}]=0,010 ;[\mathrm{Mg}]=0,140 ;[\mathrm{Ni}]=1,5$ e $[\mathrm{Zn}]=0,001$, em níveis de concentração semelhantes aos licores industriais obtidos pelo processo HPAL. Os reagentes de grau analítico, marca Synth $\left(\mathrm{NiSO}_{4} .6 \mathrm{H}_{2} \mathrm{O}, \quad \mathrm{CoSO}_{4} .7 \mathrm{H}_{2} \mathrm{O}, \quad \mathrm{MnSO}_{4} \cdot \mathrm{H}_{2} \mathrm{O}, \quad \mathrm{MgSO}_{4} .7 \mathrm{H}_{2} \mathrm{O}\right.$, $\mathrm{CuSO}_{4} .5 \mathrm{H}_{2} \mathrm{O}, \mathrm{ZnSO}_{4} .7 \mathrm{H}_{2} \mathrm{O}, \mathrm{CaSO}_{4} .2 \mathrm{H}_{2} \mathrm{O}, \mathrm{H}_{2} \mathrm{SO}_{4}$ ) foram solubilizados em água destilada e, em seguida, o licor foi filtrado para remoção de eventuais sólidos em suspensão.

\subsection{Fase orgânica}

Os extratantes Cyanex 272, fornecido pela Cytec Canada, e ácido naftênico, marca SigmaAldrich, foram solubilizados em n-heptano (marca Synth, grau analítico). Variaram-se em cada um dos três ensaios de extração por solventes, os níveis de concentração de Cyanex 272 e ácido naftênico (em \% v/v): 20 e 0; 0 e 10; 20 e 10, respectivamente. Durante a realização dos ensaios 
de extração por solventes, não foi observada formação de terceira fase. Portanto, o uso de modificadores para preparação das soluções orgânicas foi dispensável.

\subsection{Ensaios de extração por solventes}

Os ensaios de extração por solventes foram conduzidos colocando-se em contato, em um reator de vidro de 1L, volumes iguais do licor sintético sulfúrico com a solução orgânica (200 mL de cada fase). A razão entre os volumes das fases aquosa e orgânica (A/O) foi mantida unitária. $\mathrm{O}$ reator foi acoplado a um banho-maria digital (marca Kacil, modelo BM-02), que foi ajustado para que as soluções atingissem uma temperatura igual a $50^{\circ} \mathrm{C}$, similar à utilizada industrialmente nos processos de separação utilizando-se somente Cyanex 272. No momento em que as soluções atingiram a temperatura especificada, iniciou-se a agitação das fases, que foi mantida durante 5 minutos, com o auxilio de um agitador mecânico (velocidade de $400 \mathrm{rpm}$, agitador marca Ika, modelo RW 20N). Esse tempo é suficiente para se alcançar o equilíbrio líquido-líquido, conforme verificado em ensaios preliminares. Posteriormente, as soluções foram deixadas em repouso por 3 minutos para promover a separação das fases (Mansur e Dorella, 2007). O pH do licor sintético sulfúrico foi medido com o auxílio de um pHmetro (marca Quimis, modelo 0400AS). Foram recolhidas alíquotas de $10 \mathrm{~mL}$ do licor em valores de $\mathrm{pH}$ aproximadamente iguais a 2,0;3,0;3,5; 4,$0 ; 4,5 ; 5,0 ; 5,5 ; 6,0 ; 6,5$ e 7,0. Durante a realização dos ensaios de extração por solventes, foi observada uma pequena evaporação do n-heptano, mas a razão entre os volumes das fases aquosa e orgânica manteve-se inalterada $(\mathrm{A} / \mathrm{O}=1)$, em decorrência da coleta de amostras apenas da fase aquosa. $\mathrm{O}$ pH do licor foi aumentado gotejando-se solução de 5 e $10 \mathrm{~mol} / \mathrm{L}$ de $\mathrm{NaOH}$ (marca Synth, grau analítico), durante a agitação das fases. A concentração dos metais na fase aquosa foi determinada quantitativamente por Espectrofotometria de Absorção Atômica (espectrofotômetro marca GBC, modelo Avanta), enquanto que a concentração dos metais na fase orgânica foi calculada por balanço de massa a partir dos valores determinados analiticamente da fase aquosa.

\section{RESULTADOS E DISCUSSÃO}

\subsection{Pré-purificação do licor sulfúrico com Cyanex 272}

Na Figura 1, são apresentadas as curvas de extração dos metais contidos no licor sintético sulfúrico pela fase orgânica contendo Cyanex $272(20 \%$ v/v) como extratante, variando-se o pH do licor entre 2,0 e 7,0. 


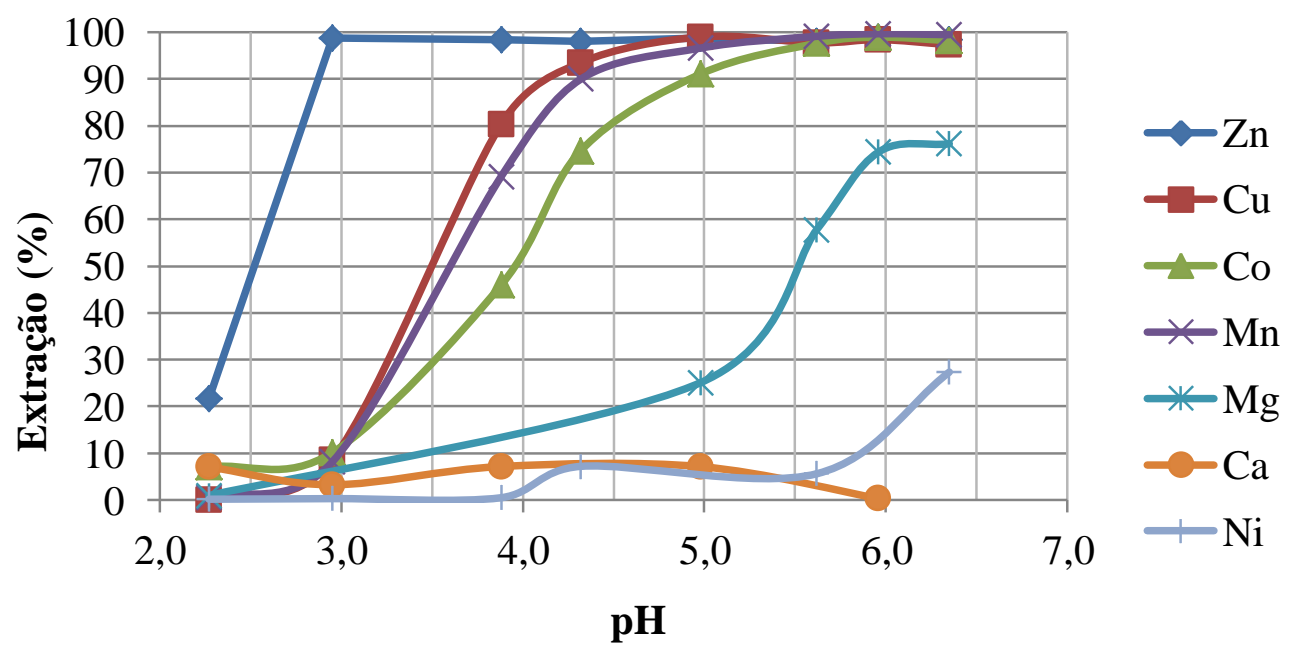

Figura 1 - Extração dos metais $\mathrm{Ca}, \mathrm{Co}, \mathrm{Cu}, \mathrm{Mn}, \mathrm{Mg}$, Ni e $\mathrm{Zn}$ contidos no licor sintético sulfúrico, em função do $\mathrm{pH}$, pelo Cyanex $272\left(20 \%\right.$ v/v) $\left(\mathrm{T}=50^{\circ} \mathrm{C}\right.$ e $\left.\mathrm{A} / \mathrm{O}=1\right)$.

Observa-se que o Cyanex 272 (20\% v/v) é seletivo para promover a extração preferencial de cobalto em relação ao níquel (extrações inferiores a 0,5\%), numa faixa de pH entre 2,0 e 4,0, corroborando os estudos realizados por Devi et al. (1998) e Nayl (2010). Nestas condições de acidez da fase aquosa, a seletividade do Cyanex $272(20 \%$ v/v), em detrimento a remoção do níquel do licor, também é verificada para os metais cobre, manganês e zinco, confirmando os resultados apresentados por Mantuano et al. (2008). Os fatores de separação $\beta_{\text {Metal/Ni mostrados }}$ na Tabela 1 revelam que a condição de acidez ótima para realizar a pré-purificação do licor em relação a esses metais ocorre em $\mathrm{pH}=3,9$ (valor próximo ao industrial), que corresponde aos maiores valores do $\beta_{\mathrm{Metal} / \mathrm{Ni}}$ indicando que menores teores de níquel são extraídos conjuntamente com essas espécies metálicas. A pré-purificação do licor pode ser realizada em 2 ou 3 estágios de contactação.

Tabela 1 - Fatores de separação do $\mathrm{Co}, \mathrm{Cu}, \mathrm{Mn}$ e $\mathrm{Zn}$ contidos no licor em relação ao níquel com Cyanex $272(20 \%$ v/v)

\begin{tabular}{|c|c|c|c|c|}
\hline $\mathrm{pH}$ & $\beta_{\mathrm{Co} / \mathrm{Ni}}$ & $\beta_{\mathrm{Cu} / \mathrm{Ni}}$ & $\beta_{\mathrm{Mn} / \mathrm{Ni}}$ & $\beta_{\mathrm{Zn} / \mathrm{Ni}}$ \\
\hline 2,9 & 37 & 32 & 30 & 27066 \\
\hline $\mathbf{3 , 9}$ & $\mathbf{1 7 3}$ & $\mathbf{8 2 9}$ & $\mathbf{4 5 5}$ & $\mathbf{1 1 8 6 5}$ \\
\hline 4,3 & 38 & 186 & 116 & 678 \\
\hline
\end{tabular}

Observa-se extração de magnésio, em torno de 70-80\% mas conjuntamente com o níquel (aproximadamente 25-30\%), numa faixa de $\mathrm{pH}$ entre 5,0 e 6,0, enquanto o cálcio praticamente não é removido do licor, extrações inferiores a 10\%, em toda a faixa de $\mathrm{pH}$ analisada, entre 2,0 e 7,0. Desta forma, tem-se que Cyanex 272 (20\% v/v) não é seletivo para a extração desses metais, corroborando Flett (2005). 


\subsection{Purificação de níquel}

Almejando-se a purificação do licor em relação ao níquel diante dos contaminantes, cálcio e magnésio, são apresentadas, na Figura 2, as curvas de extração dessas três espécies metálicas utilizando-se ácido naftênico (10\% v/v) e misturas entre ácido naftênico (10\% v/v) e Cyanex 272 $(20 \% \mathrm{v} / \mathrm{v})$, variando-se o $\mathrm{pH}$ do licor entre 3,5 e 7,0 aproximadamente.

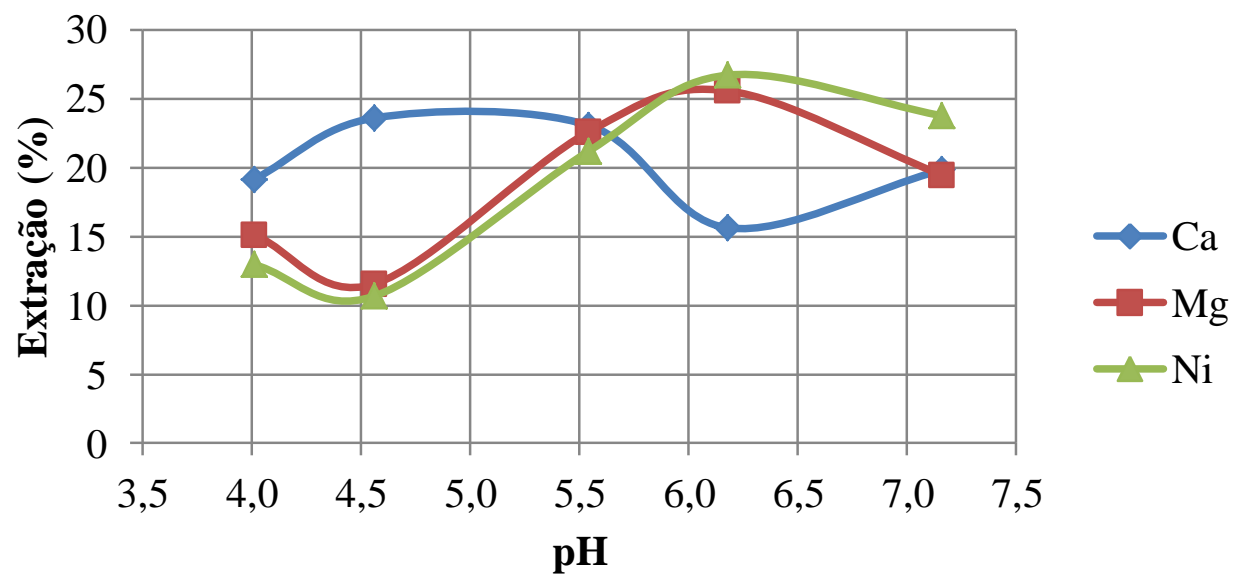

(a)

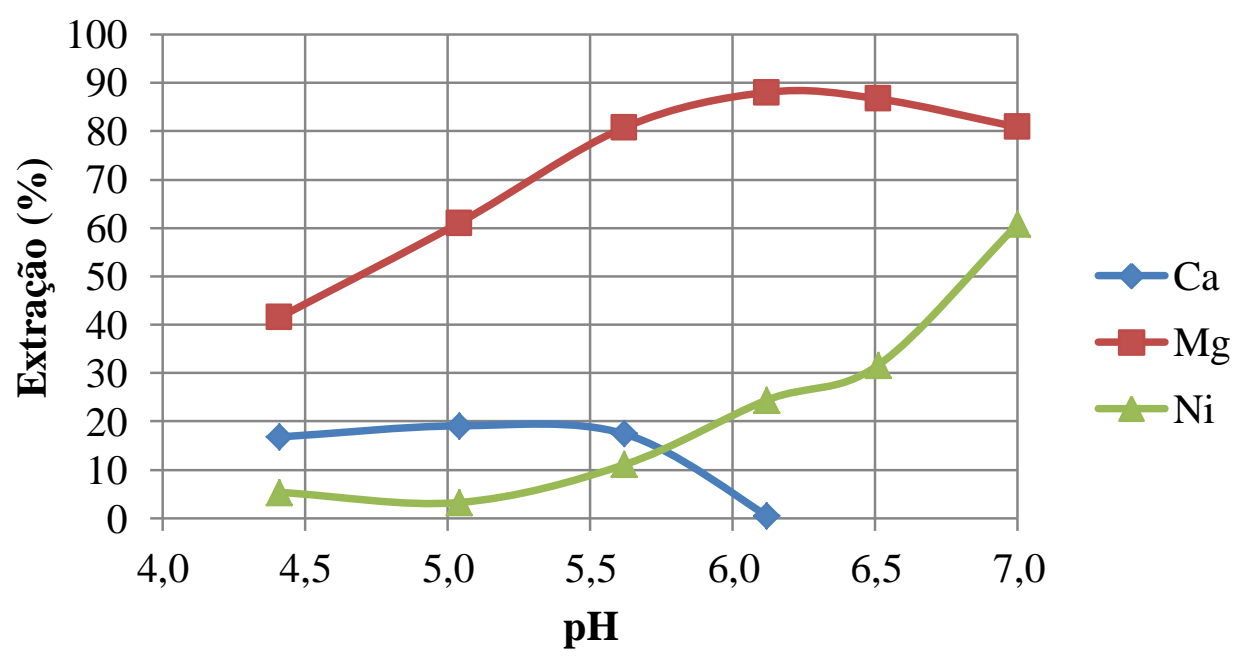

(b)

Figura 2 - Extração de cálcio, magnésio e níquel contidos no licor sulfúrico, em função do pH, utilizando-se: (a) 10\% v/v de ácido naftênico, e (b) 10\% v/v de ácido naftênico e 20\% v/v de Cyanex $272\left(\mathrm{~T}=50{ }^{\circ} \mathrm{C}\right.$ e $\left.\mathrm{A} / \mathrm{O}=1\right)$. 
De uma maneira geral, observa-se, com base na Figura 2(a), alguma afinidade do ácido naftênico $(10 \% \mathrm{v} / \mathrm{v})$ na extração de cálcio, sendo restrita a condições de maior acidez do licor $(4,0<\mathrm{pH}<5,5)$. À medida que o $\mathrm{pH}$ da fase aquosa é aumentado de 5,5 até 7,5, porém, a pouca afinidade apresentada pelo ácido naftênico pelo cálcio diminui ainda mais. Já com relação ao magnésio e níquel, ambos são extraídos conjuntamente. A baixa seletividade do ácido naftênico na faixa de condições operacionais estudada resulta em fatores de separação, $\beta_{\mathrm{Ca} / \mathrm{Ni} \text { e }} \beta_{\mathrm{Mg} / \mathrm{Ni}}$, inferiores a 10, logo, a utilização de ácido naftênico para a purificação do níquel frente aos metais alcalino terrosos é inviável.

A mistura de 20\% v/v de Cyanex 272 com 10\% v/v de ácido naftênico, Figura 2(b), alterou significativamente o comportamento de extração dos metais cálcio, magnésio e níquel. Por exemplo, as extrações de cálcio, magnésio e níquel atingiram, respectivamente, $20 \%$, 60\% e 3\% em pH igual a 5,0. Os fatores de separação mostrados na Tabela 2 indicam ser essa condição operacional a mais favorável em termos de seletividade, o que possibilitaria a purificação do licor de níquel na operação em estágios em contracorrente. A partir de $\mathrm{pH}=5,5$, porém, observa-se uma diminuição na extração de cálcio e aumento na extração de níquel, ocorrida provavelmente em função de troca catiônica entre esses dois metais.

Tabela 2 - Fatores de separação dos metais Ca, Mg e Ni utilizando-se 10\% v/v de ácido naftênico com $20 \%$ v/v de Cyanex 272

\begin{tabular}{|c|c|c|}
\hline $\mathrm{pH}$ & $\beta_{\mathrm{Ca} / \mathrm{Ni}}$ & $\beta_{\mathrm{Mg} / \mathrm{Ni}}$ \\
\hline 4,4 & 4 & 13 \\
\hline $\mathbf{5 , 0}$ & $\mathbf{7}$ & $\mathbf{4 7}$ \\
\hline 6,1 & 0 & 23 \\
\hline
\end{tabular}

\section{CONCLUSÕES}

A purificação de níquel contido em soluções aquosas sulfúricas contendo cálcio, cobalto, cobre, manganês, magnésio, níquel e zinco, em níveis de concentrações similares aos encontrados nos licores industriais obtidos pelo processo HPAL após a etapa de remoção de ferro foi investigada por extração por solventes utilizando-se os extratantes Cyanex 272 e ácido naftênico. As principais conclusões obtidas são:

- O Cyanex $272(20 \%$ v/v) é seletivo para promover a pré-purificação do licor sintético sulfúrico, em $\mathrm{pH}=3,9$ e $50^{\circ} \mathrm{C}$, em relação aos metais zinco, cobre, cobalto e manganês, uma vez que baixos teores de níquel são extraídos conjuntamente com essas espécies metálicas, em torno de $0,5 \%$. A operação deve ocorrer em estágios sucessivos em contracorrente. $\mathrm{O}$ Cyanex 272, porém, apresenta baixa seletividade na purificação do níquel diante dos contaminantes cálcio e magnésio;

- A purificação do níquel frente ao cálcio e magnésio mostrou-se ineficiente ao se utilizar $10 \%$ v/v de ácido naftênico, por apresentar baixa seletividade em toda a faixa de $\mathrm{pH}$ analisada, 


\section{9 a 22 de outubro de 2014 \\ Florianópolis/SC}

entre 3,5 e 7,0 ;

- A mistura de 20\% v/v de Cyanex 272 com 10\% v/v de ácido naftênico mostrou-se promissora na purificação do licor sintético em relação ao níquel, em pH 5,0, na temperatura de $50^{\circ} \mathrm{C}$ e em estágios sucessivos em contracorrente. Nesta condição, cerca de $20 \%$ de cálcio e $60 \%$ de magnésio são extraídos num único estágio, com perda de aproximadamente $3 \%$ de níquel.

- Os resultados obtidos permitiram a identificação de um possível sistema extrator aplicável à purificação de níquel. Além da otimização das condições operacionais, a realização de ensaios de reextração e a avaliação da operação contínua empregando-se baterias de misturadores-decantadores com licores de lixiviação reais se faz, portanto, necessária para comprovar a eficiência do mesmo.

\section{AGRADECIMENTOS}

Os autores deste trabalho agradecem ao CNPq, FAPEMIG, CAPES, CNPq (CT Mineral, Processo 550243/2011-9), INCT Acqua (Instituto Nacional de Ciência e Tecnologia em Recursos Minerais, Água e Biodiversidade, www.acqua-inct.org), à Cytec pelo fornecimento de Cyanex 272 e ao Laboratório de Análises Químicas do DEMET/UFMG.

\section{REFERÊNCIAS}

CHENG, C.Y. Solvent extraction of nickel and cobalt with synergistic systems consisting of carboxylic acid and aliphatic hydroxyoxime. Hydrometallurgy, v. 84, p. 109-117, 2006.

DEVI, N.; NATHSARMA, K.; CHAKRAVORTTY, V. Separation and recovery of cobalt (II) and nickel (II) from sulphate solutions using sodium salts of D2EHPA, PC 88A and Cyanex 272. Hydrometallurgy, v. 49, p. 47-61, 1998.

FLETT, D.S. Solvent extraction in hydrometallurgy: the role of organophosphorus extractants. $J$. Org. Chem., v. 609, 2426-2438, 2005.

LO, T.C.; BAIRD, M.H.I.; HANSON, C. Handbook of solvent extraction. USA: John Wiley \& Sons, 1983.

MANSUR, M.B.; DORELLA, G. A Study of the separation of cobalt from spent Li-ion batteries residues. J. Power Sources, v. 170, p. 210-215, 2007.

MANTUANO, D.P., DORELlA, G., ELIAS, R.C.A., MANSUR, M.B., Analysis of a hydrometallurgical route to recover base metals from spent rechargeable batteries by liquidliquid extraction with Cyanex 272. J. Power Sources, v. 159, p. 1510-1518, 2008.

MOSKALYK, R.R.; ALFANTAZI, A.M. Nickel laterite processing and electrowinning practice. Minerals Engineering, v. 15, p. 593-605, 2002.

NAYL, A.A. Extraction and separation of $\mathrm{Co}(\mathrm{II})$ and $\mathrm{Ni}(\mathrm{II})$ from acidic sulfate solutions using Aliquat 336. J. Haz. Mat., v. 173, p. 223-230, 2010.

NDLOVU, B.; MAHLANGU, T. Calcium and magnesium rejection from sulphate solutions in lateritic nickel solvent extraction using Versatic 10 acid-Lix ${ }^{\circledR} 84$ IC system. Template J., v. 108, p. 223-227, 2008. 
RYDBERG, J.; COX, M.; MUSIKAS, C.; CHOPPIN, G.R. Principles and practices of solvent extraction. New York: Marcel Dekker, 2004.

U.S. Geological Survey, Mineral Commodity Summaries, February 2014, http://minerals.usgs.gov/minerals/pubs/commodity/nickel/mcs-2014-nicke.pdf, acessado em 24/04/2014. 